\title{
Variabilidade temporal do perfil de dunas na Praia do Cassino, RS, com auxílio de videomonitoramento Argus
}

\author{
Pedro V. GUIMARÃES ${ }^{1}$, Pedro S. PEREIRA² ${ }^{2}$ Lauro J. CALLIARI ${ }^{1} \&$ Nisia KRUSCHE ${ }^{3}$
}

1. Instituto de Oceanografia, Universidade Federal do Rio Grande. Caixa Postal 474, CEP 96201-900, Rio Grande, RS. E-mail:pvguima@ gmail.com, lcalliari@log.furg.br.

2. Laboratório de Oceanografia Geológica, Universidade Federal de Pernambuco. Av. Prof. Moraes Rego, 1235, CEP 50670-901, Cidade Universitária, Recife, PE. E-mail: psppraias@gmail.com.

3. Centro de Ciências Computacionais, Universidade Federal do Rio Grande. Campus Carreiros, CaixaPostal 474, CEP 96201-900, Rio Grande, RS. E-mail: nkrusche@furg.br.

Recebido em 01/2014. Aceito para publicação em 09/2014.

Versão online publicada em 04/12/2014 (www.pesquisasemgeociencias.ufrgs.br)

\begin{abstract}
Resumo - A dinâmica sedimentar em dunas costeiras é um processo complexo que exige a análise de vários fatores em diferentes escalas temporais. A análise de um banco de dados morfológicos sequenciais de três anos, realizados em um setor de dunas da praia do Cassino, localizada ao sul do Rio Grande do Sul, Brasil (RS), permitiu identificar a evolução espaço-temporal do perfil de dunas, que apresentou um comportamento predominantemente acrescional médio de $14,86 \mathrm{~m}^{3} / \mathrm{m}$ por ano. Dados de ventos e Índice de Oscilação Niño (ION) mostram que esses componentes foram os principais agentes modeladores durante esse período. As técnicas de processamento digital de imagens associadas ao sistema Argus permitiram verificar o aumento da densidade vegetacionalna região que juntamente com os fatores físicos observados contribuíram para o aumento de volume de areia dasdunas costeiras.

Palavras-chave: morfodinâmica de dunas, videomonitoramento, sistema acrescivo, Índice de Oscilação Niño, perfil dissipativo.
\end{abstract}

\begin{abstract}
Temporal Changes in a CASSINo BeACH, RS, DUNES PROFILE With ARguS SYSTEM VIDEO-MonitoRing ASSISTANCE. The dynamics of coastal sand dunes is a complex process that requires examining several processes at different scales. The analysis of three years morphological database of beach profiles at Cassino Beach, located in the south of Rio Grande do Sul state (RS), Brazil, identified an accretional behavior with an average of $14.86 \mathrm{~m}^{3} / \mathrm{m}$ per year. Wind data and Oceanic Niño Index (ONI) showed that these components were the main modeling agents during this period. Digital imaging processing techniques related to the Argus system allowed to verify the increase of vegetation density and how some other factors contributed to increase coastal dune sand volume.
\end{abstract}

Keywords: dunes morphodynamic, video-monitoring, depositional system, Oceanic Niño Index (ONI), dissipative profile.

\section{Introdução}

Inseridas no sistema costeiro, as dunas são feições geomorfológicas resultantes da acumulação de areias transportadas pelo vento, constituindo um ambiente transicional entre os sistemas marinho e terrestre no qual exercem múltiplas funções. Dentre elas destacam-se a proteção dos ecossistemas costeiros e complexos urbanos adjacentes, as atividades de recreação e turismo, e a de habitat preferencial de várias espécies de fauna e flora.

No Brasil, áreas de dunas constituem terrenos protegidos por legislação ambiental (resolução CONA$\mathrm{MA} \mathrm{n}^{\circ}$ 303, 20 de março de 2002), contudo, frequentemente são observados conflitos entre a preservação e projetos de infraestrutura da orla. Associadas à paisagem natural, desde 1988 as dunas da praia do Cassino, no Rio Grande do Sul, fazem parte de um processo de manejo e conservação realizado pela associação priva- da sem fins lucrativos, o Núcleo de Educação e Monitoramento Ambiental (NEMA). O objetivo desse projeto é a recuperação de áreas que entre 1970 e 1980 foram intensamente degradadas pela ação antrópica (Carvalho et al., 2008).

O aporte contínuo de sedimentos na praia, juntamente com um transporte eólico, predominantemente no sentido praia-dunas (ou com componente perpendicular à linha de costa), resulta no realocamento dos sedimentos nas dunas embrionárias e frontais, normalmente fixadas por vegetação (Carter, 1988). Assim, ao longo do tempo, o vento é responsável pelo crescimento das dunas e evolução para campo de dunas frontais, promovendo gradualmente aprogradação do perfil de dunas. Portanto, nessa análise, além dos processos físicos que condicionam esse sistema, a presença da vegetação também possui importância na dinâmica sedimentar, pois a vegetação tem papel de fixar o sedimento, dificultando que o vento o remobilize. 
As variações das condições climáticas e oceanográficas constituem importante função na evolução do balanço sedimentar ao longo do tempo. Diferentes orientações do vento podem resultar em transporte paralelo ou oblíquo em direção à costa, sendo que este último aumenta o potencial para a formação das dunas frontais. Calliari et al. (2005) assinalam que, no litoral médio do RS, a direção e intensidade do vento NE associadas à orientação da linha de costa são os principais fatores responsáveis pelo aumento das dunas frontais em determinados trechos da costa. Secundariamente, aparecem a largura da praia e o nível de umidade nos sedimentos como as variáveis mais importantes no controle do suprimento de areia para as dunas frontais. Consequentemente, é esperado que oscilações mensais e sazonais na direção e intensidade do vento bem como alterações devido a eventos de El Niño e La Niña, também sejam responsáveis por causar modificações no estoque sedimentar das dunas.

A falta de monitoramento contínuo, devido a problemas de logística numa costa tão extensa como a do RS, impede que se conheçam as causas das variações temporal do campo de dunas. Entretanto, a partir de 2005, com a instalação de um sistema de videomonitoramento na praia do Cassino (Guedes et al., 2009) um setor desta praia, conhecido como Querência, tem sido monitorado sistematicamente, permitindo assim avaliar o comportamento dos perfis monitorados em função do regime de ventos epossíveis oscilações cli- máticas. Portanto, o objetivo base deste trabalho é analisar e discutir o comportamento e evolução do perfil subaéreo da praia do Cassino durante os anos de 2005 a 2007, identificando, a médio prazo, as componentes dinâmicas atuantes na porção subaérea desse setor praial.

\section{2 Área, materiais e métodos}

\section{1 Área}

A praia do Cassino localiza-se no litoral sul do estado do Rio Grande do Sul, RS, sendo o início de uma praia ininterrupta que se prolonga até a fronteira com o Uruguai. Seus limites, norte e sul, são respectivamente os molhes de Rio Grande, na desembocadura da lagoa dos Patos e o arroio Chuí. Esse trabalho foi desenvolvido no setor conhecido como Querência onde se localiza a estação de videomonitoramento do Sistema Argus bem como vários marcos topográficos utilizados no monitoramento sistemático dos perfis praiais (Fig. 1). 0 estudo concentrou-se em aproximadamente 300 $\mathrm{m}$ de pós-praia, entre o limite superior do estirâncio e as dunas frontais vegetadas. Processos eólicos dominam nesta área que é frequentemente afetada por inundações durante eventos associados a tempestades do quadrante sul que provocam elevação do nível do mar, as chamadas marés meteorológicas.

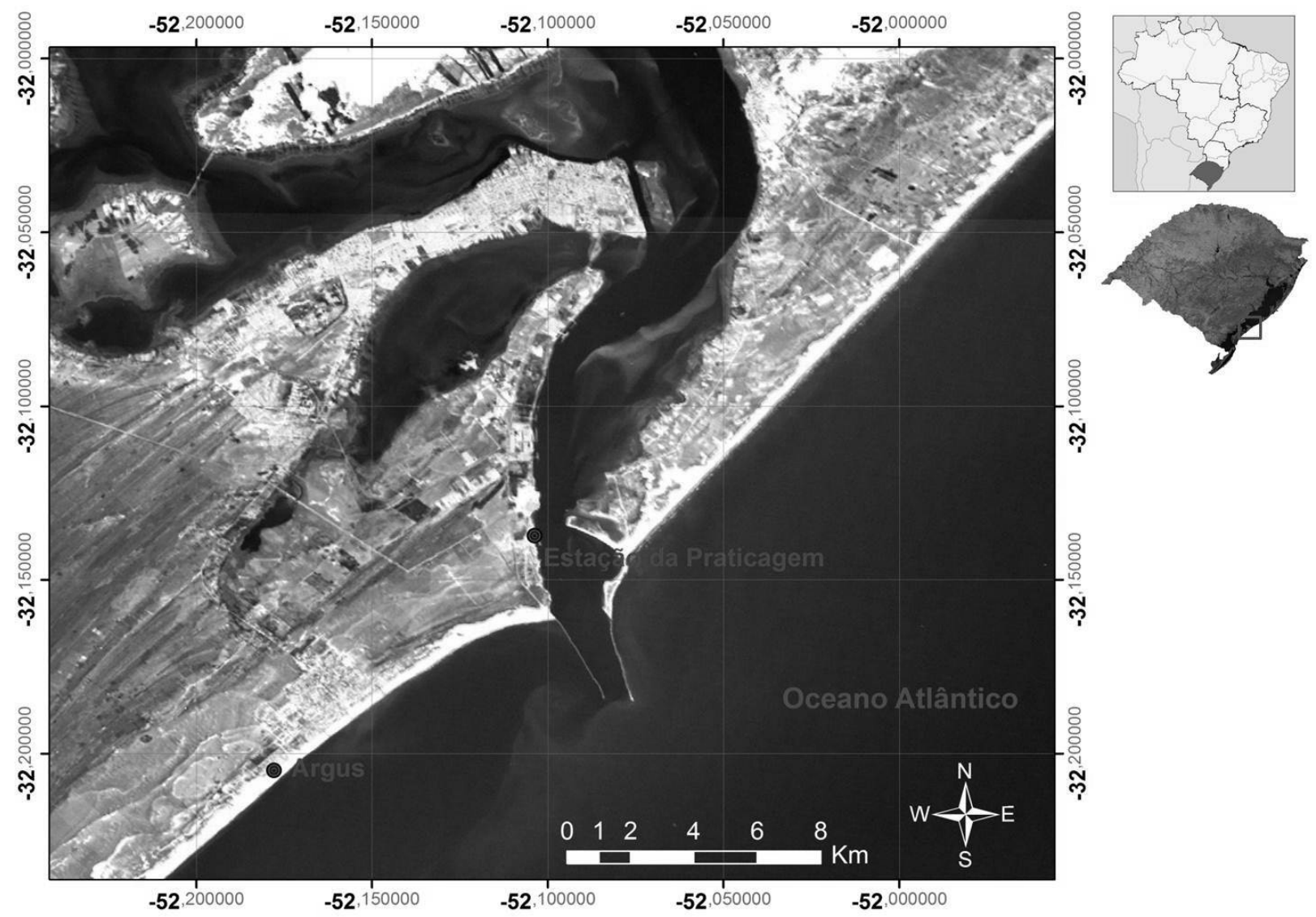

Figura 1. Localização da Praia do Cassino, ao sul da desembocadura da Lagoa dos Patos. A figura indica a localização das câmeras Argus e da localização da praticagem da barra sobre uma imagem LANDSAT TM RGB (137). 
A região apresenta um regime de micromarésendo dominada por ondas com altura significativa de 1,5 $\mathrm{m}$. Areia muito fina e fina são as classes granulométricas predominantes. De acordo com a classificação morfodinâmica de Wright \& Short (1984) a praia comporta-se como dissipativa apresentando múltiplos bancos (Calliari \& Klein, 1993; Pereira et al.,2012). As marés meteorológicas que frequentemente excedem a maré astronômica são causadas pela presença de sistemas de baixa pressão sobre o oceano e alta pressão sobre o continente os quais se deslocam para o norte ou leste. Nestas ocasiões ocorrem inundações que produzem erosão acentuada no cordão de dunas frontais.

Os padrões da circulação atmosférica no sul do Brasil são controlados por dois anticiclones os quais se alternam sazonalmente: o Anticiclone Tropical do Atlântico Sul (ATAS) e o Anticiclone Polar Migratório (APA) (Nimer, 1989; Tomazelli, 1993).0 ATAS é um centro de alta pressão composto por uma massa de ar quente e úmida prevalente durante os meses quentes da primavera e verão com ventos predominantemente de E e NE (Zhou\&Lau, 1998). O APA é um centro de alta pressão alimentado por massas de ar frio da Antártica. Durante as estações mais frias do outono e inverno,o APA é mais ativo e consequentemente os ventos ciclônicos de S e SW, produzidos pelas frentes frias prevalecem neste período (Kruscheet al., 2002).

\subsection{Dados meteorológicos}

Os dados de vento foram obtidos da estação da Praticagem da Barra, localizada na margem oeste do canal de navegação da barra do Rio Grande (Fig. 1). Nesta estação as médias horárias da intensidade e direção são obtidas no topo de uma torre de $22 \mathrm{~m}$ de altura.

\section{3 Índice de Oscilação Niño}

Os dados de anomalia de temperatura da superfície do mar servem para distinguir períodos de El Niño (quente) e La Niña (frio). O Índice de Oscilação Niño (ION) representa a média móvel a cada três meses da temperatura superficial das águas do Pacífico equatorial (entre $50^{\circ} \mathrm{N}, 50^{\circ} \mathrm{S}, 170^{\circ} \mathrm{W}$ e $120^{\circ} \mathrm{W}$ ). Os dados utilizados encontram-se disponíveis na página de internet da NationalOceanicandAtmosphericAdministration (NOAA, 2010).

\subsection{Perfis de praia}

Foi utilizado um banco de dados de perfis topográficos mantido pelo grupo de pesquisa do Laboratório de Oceanografia Geológica da Universidade Federal do Rio Grande. 0 banco de dados é composto por levantamentos efetuados entre 07 de março de 2005 a 27 de fevereiro de 2007, sendo que as datas dos levantamentos não estão igualmente distribuídas no tempo. Todos os perfis foram feitos sob um mesmo alinhamen- to, transversal à linha de costa, usando estação total e prisma ótico. Além disso, os dados foram interpolados a um espaçamento regular de um metro ao longo da direção transversal à costa. A estação total foi posicionada sobre um marco sobre as dunas frontais, em frente às câmeras de vídeo Argus. A posição desse marco é definida como a origem do sistema de coordenadas local $(0,0)$ que é o mesmo usado como referência do sistema de coordenadas do sistema Argus.A partir desse banco de perfis topográficos foi estimado o volume para uma largura de um metro da área, calculada a partir da integral numérica pelo método do trapézio.

\subsection{Vídeomonitoramento}

O sistemaArgus consiste num conjunto de câmeras de vídeo instaladas em lugares altos da zona costeira ou em torres capturando imagens da praia e da zona de arrebentação em vários locais do globo (Holman \& Stanley, 2007). A estação Argus do Cassino é constituída por quatro câmeras de vídeo instaladas no topo de uma torre de $14 \mathrm{~m}$ de altura. Esta estação está operacional desde março de 2005 em frente à Estação Marinha de Aquicultura (EMA) e captura imagens durante as horas do dia com visibilidade.

São três os principais produtos do sistema Argus: uma imagem instantânea (snapshot), uma imagem de longa exposição de 10 minutos (timex) a qual é obtida através da média de 600 imagens instantâneas coletadas a cada segundo durante 10 minutos, e o terceiro tipo de imagem, a variance gerada a partir das regiões que estão mudando durante os 10 minutos de coleta das 600 imagens que compõem a timex. A variance representa o desvio padrão de todas as imagens usadas para compor a timex (Fig.2A).

Cada imagem pode ser retificada e combinada em uma única imagem plana. Holand et al. (1997) apresentam uma descrição detalhada de como cada imagem pode ser retificada e combinada gerando um único plano através da resolução de equações colineares (Fig. 2B) transformando uma imagem bidimensional em um sistema com coordenadas reais tridimensionais considerando as distorções radiais da lente das câmeras.

Na Praia do Cassino a imagem é retificada para uma grade regular de $1 \times 1 \mathrm{~m}$. 0 eixo principal da imagem é paralelo ao longo da praia, tendo uma orientação nordeste-sudoeste enquanto que o eixo normal apresenta a mesma orientação que as linhas dos perfis topográficos. Esse sistema de sensoriamento remoto permite identificar e descrever feições geomorfológicas que aparecem na praia permitindo monitorar suas mudanças temporais.

\subsection{Estudo da vegetação}

Para avaliar a variação na densidade da vegetação ao longo tempo foi realizada a ortorretificação, apenas da região entre as dunas frontais e o pós-praia, nas 
A) Imagens timex de cada câmera Argus

C1

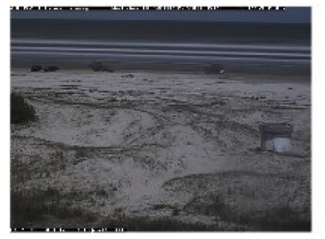

$\mathrm{C} 2$

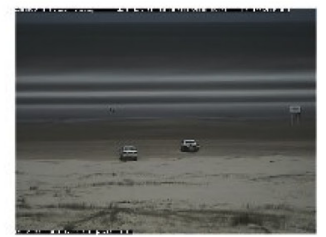

C3

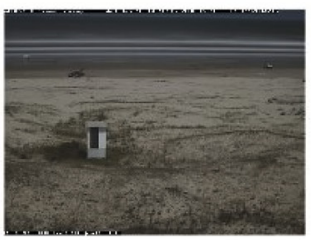

C4

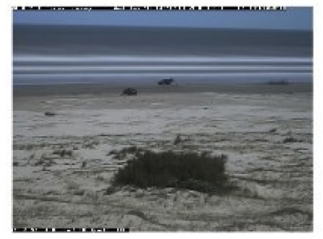

B) Mosaico ortoretificado das 4 imagens

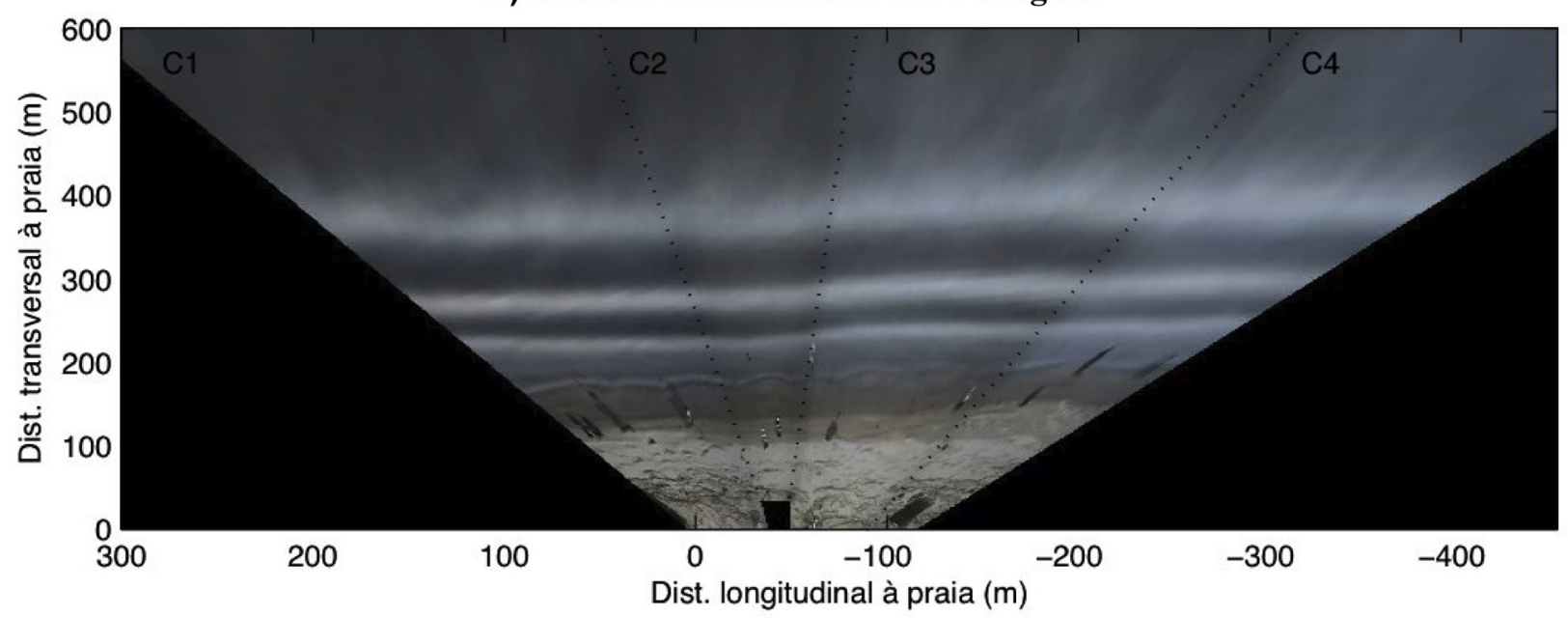

Figura 2. Imagens timex das câmeras Argus. A) Exemplo de uma imagem timex do conjunto das quatro câmeras de vídeo da estação Argus Cassino(C1 a C4); B) Mosaico ortoretificado das 4 imagens timex de cada câmera.

médias diárias (daytimex) das imagens da câmera 1, de acordo com a metodologia proposta por Holland et al. (1997, fig.3), para o dia primeiro de novembro dos anos de 2005, 2006 e 2007. Portanto, a fim de identificar como se desenvolveu a vegetação sobre o campo de dunas frontais no tempo, foi calculada a diferença pixel a pixel entre essas imagens, utilizando um recorte na banda do verde na escala de cores RGB.

Para identificar as espécies vegetais presentes, foi utilizado em campo um guia ecológico ilustrado da região produzido por Seeliger et al. (2004), juntamente com as imagens do dia 01 de novembro de 2007 e de 01 de outubro de 2010 para identificar quais as principais espécies vegetais predominavam na região durante 0 período estudado. Dessa forma, foi possível estabelecer a zonação das espécies que predominavam na região. Assume-se que o período de 3 anos é muito curto para uma grande sucessão das espécimes vegetais presentes.
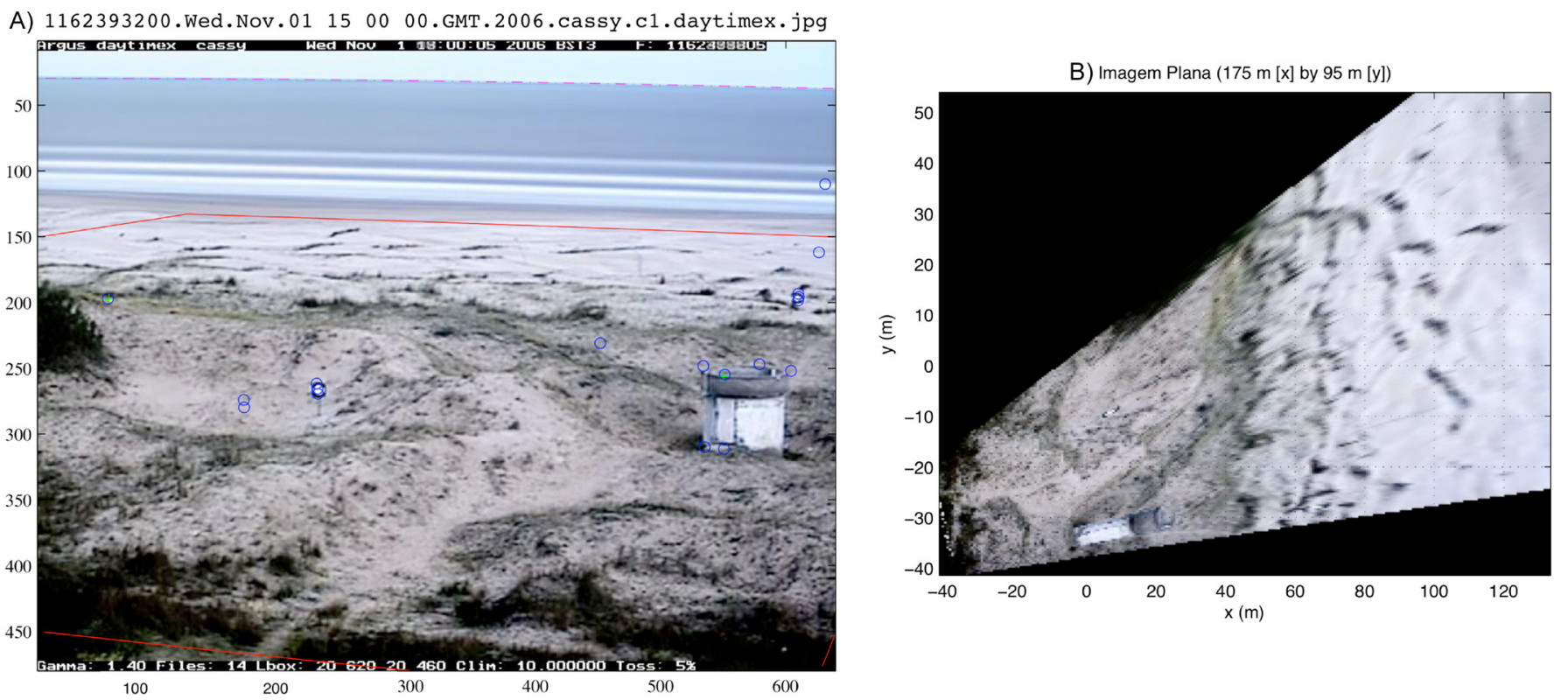

Figura 3. Imagens da câmera 1 do sistema Argus. A) daytimex (imagem composta pela média das imagens do dia); B) Imagem daytimex orto-retificação a partir da parte selecionada no interior do retângulo em vermelho da figura A. 


\subsection{Identificação das dunas}

A identificação das dunas através do sistema Argus é baseada num processo de seleção visual de cada imagem onde as dunas incipientes formadas na região da berma podem ser diferenciadas das dunas frontais. A figura 4 é um exemplo de tal diferenciação. a)

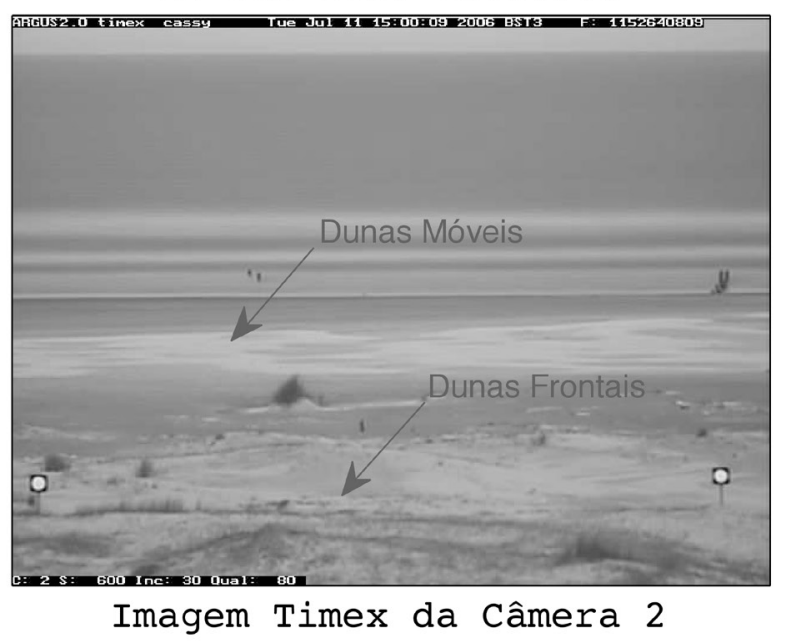

b)

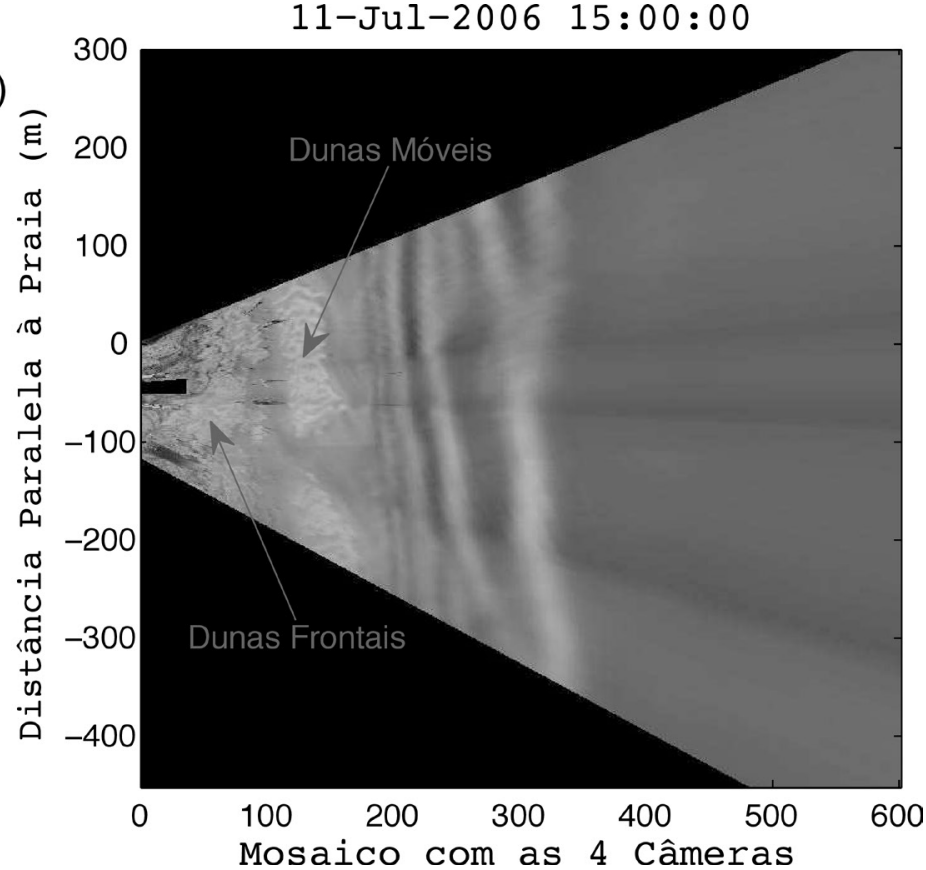

Figura 4. Imagem timex do sistema Argus para o dia 11 de Julho de 2006 as $15 \mathrm{~h}$. A) Representa uma imagem timex da câmera 2 do sistema Argus; B) Representa um mosaico formado pelas quatro câmeras no mesmo isntante de tempo. Em ambas pode-se observar a presença de dunas frontais vegetadas junto com a presença de dunas móveis sobre o pós-praia.

\section{Resultados}

Através de foto identificação das dunas incipientes no pós-praia foi possível verificar sua ocorrência e permanência nesta zona. A figura 5 refere-se a todas as ocorrências de dunas incipientes no período estudado, destacando o período da primavera de 2006, no qual foi identificado um grande número de ocorrências de tais morfologias.

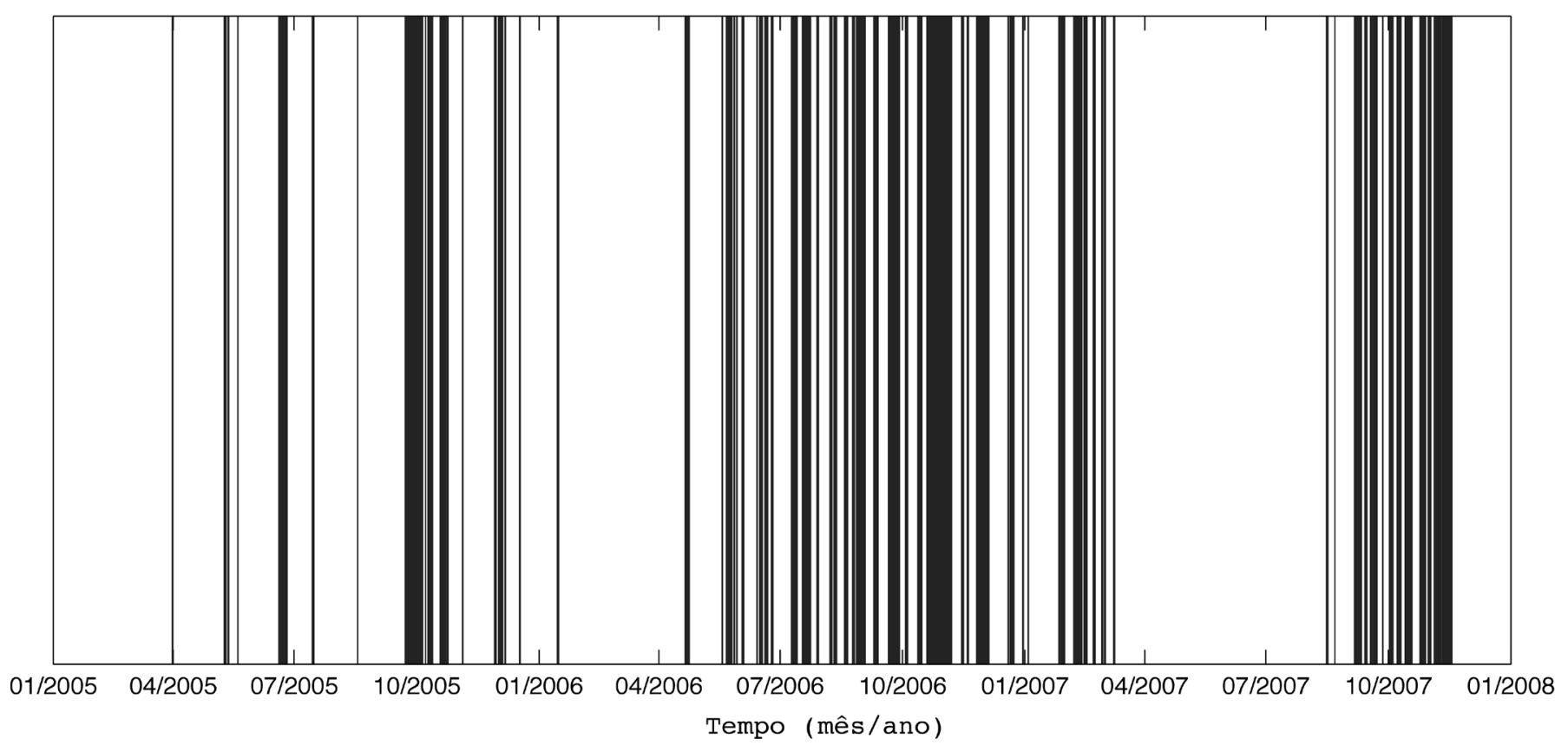

Figura 5. Ocorrência das dunas no pós-praia. As linhas azuis correspondem às imagens com a presença de dunas sobre o pós-praia, enquanto os espaços em branco representam o intervalo entre a destruição das mesmas até a formação de novas dunas. A série temporal corresponde ao período analisado de 3 de março de 2005 até 17 de novembro de 2007. 
0 aporte contínuo de sedimentos provenientes do pós-praia e zona de espraiamento em direção a terra fazem com que as dunas cresçam e evoluam para formar dunas frontais, promovendo dessa forma a progradação da costa. Esse sedimento, da porção subaérea da praia, também deve ser reposto na parte submersa, pois a perda de sedimento do estirâncio para a duna, ao longo de décadas, deve ser reposta para manter o balanço sedimentar positivo. Caso isso não aconteça, a praia sofrerá erosão devido ao embate das ondas (Psuty,1988). Lélis (2003) calculou a taxa de progradação da praia do Cassino entre 1947 e 2000, obtendo uma progradação média de 4,1 m/ano. Isso parece indicar um acréscimo no volume sedimentar na porção subaérea desta praia.

A figura 6 mostra como se comportou a topografia subaérea do terreno ao longo dos anos de 2005, 2006 e 2007. As figuras 6, 7 e 8 identificam que houve um aumento do volume de sedimento disponível na porção subaérea da praia. Na figura 6, percebe-se também que na primavera do ano de 2006 (período próximo ao início do ano de 2007) houve um aumento da quantidade de sedimento disponível na região do pós-praia, fato que também foi percebido pela identificação de dunas sobre o pós-praia, utilizando o sistema de videomonitoramentoArgus (Fig. 5).

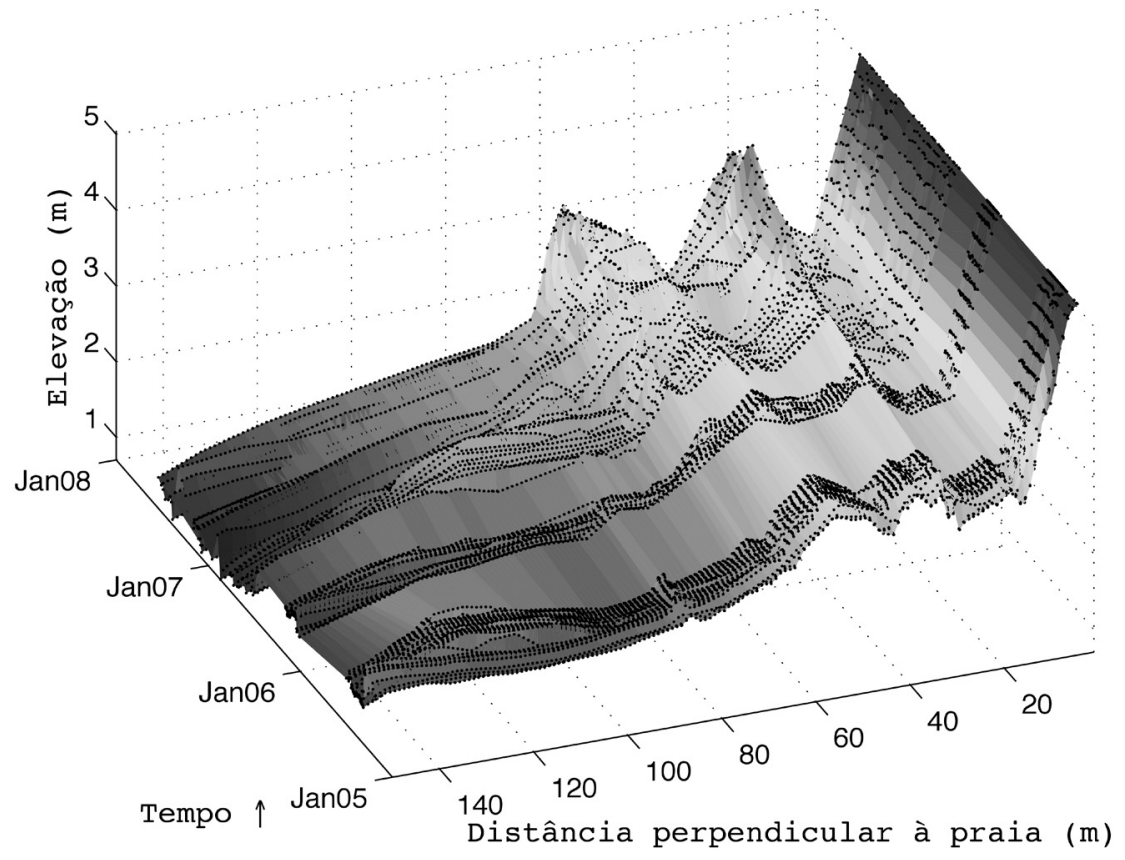

Figura 6. Evolução espaço-temporal do pós-praia e dunas frontais da praia do Cassino. As linhas pontilhadas significam que o perfil topográfico foi realizado naquele instante de tempo.

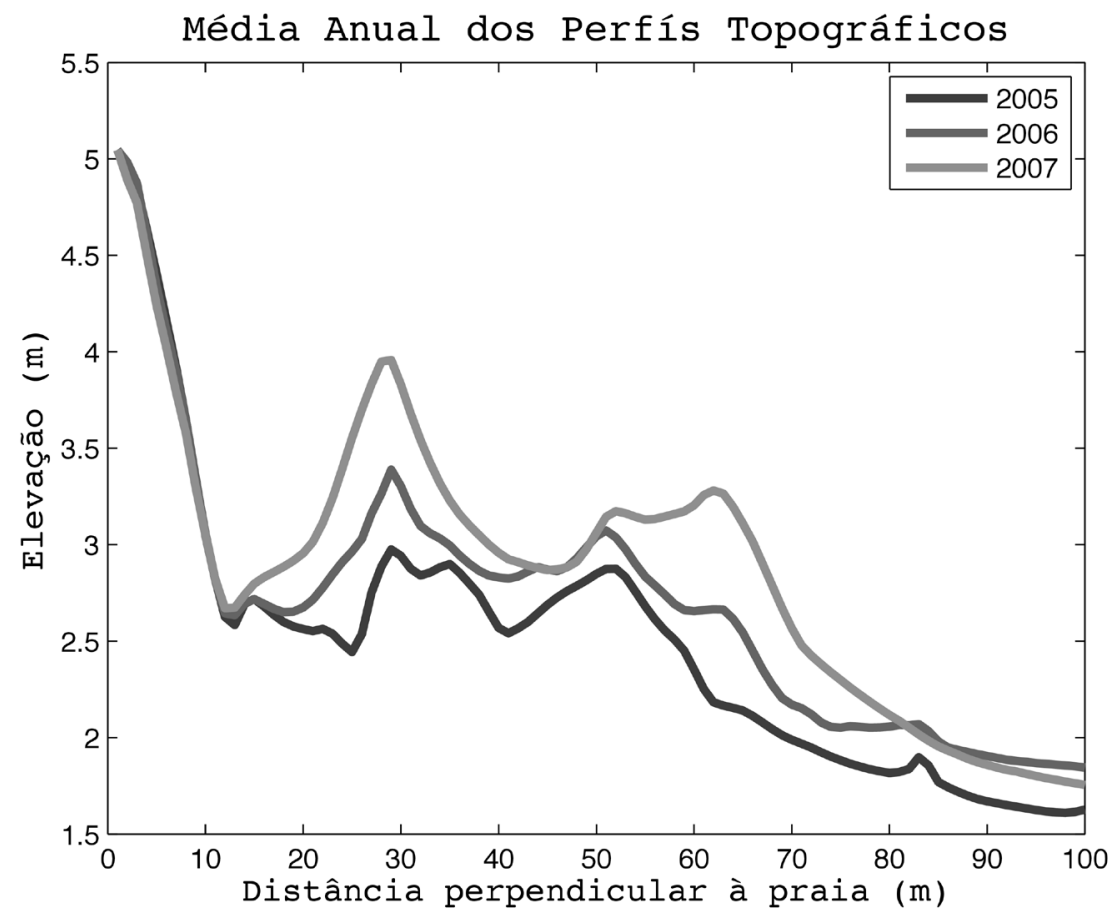

Figura 7. Perfis médios anuais obtidos sob um mesmo alinhamento na praia do Cassino nos anos de 2005, 2006 e 2007. 
Para compreender melhor as variações do estoque sedimentar ao longo do tempo foi calculada a média anual dos perfis topográficos, expostos na figura 7. Dessa forma, pode-se determinar que esse setor da praia do Cassino apresentou um caráter acrescional em sua porção subaérea. As taxas de variações médias desses perfis estão calculadas na figura 8 (para os anos de 2005 a 2007). Por conseguinte, a variação do volume sedimentar mostrou-se positiva para todo o período estudado, com taxa de acresção média de $14,86 \mathrm{~m}^{3} / \mathrm{m}$ ao ano. Essa taxa de acresção anual comportou-se praticamente constante, sendo um pouco maior no ano de $2006\left(2,3 \mathrm{~m}^{3} / \mathrm{m}\right.$ maior que a média). Todavia, percebe-se que os sedimentos não se depositaram na mesma região durante todo o período estudado. Em 2007 houve uma tendência de verticalização na deposição dos sedimentos, ou seja, eles se depositaram preferencialmente sobre as dunas frontais. Enquanto que durante o ano de 2006 o sedimento distribuiu-se mais horizontalmente, assim se assentando sobre a região do pós-praia. Consequentemente, esse sedimento livre sobre a região do pós-praia se encontrava na forma de dunas incipientes, conforme observado nas imagens do sistema Argus (Fig.5).

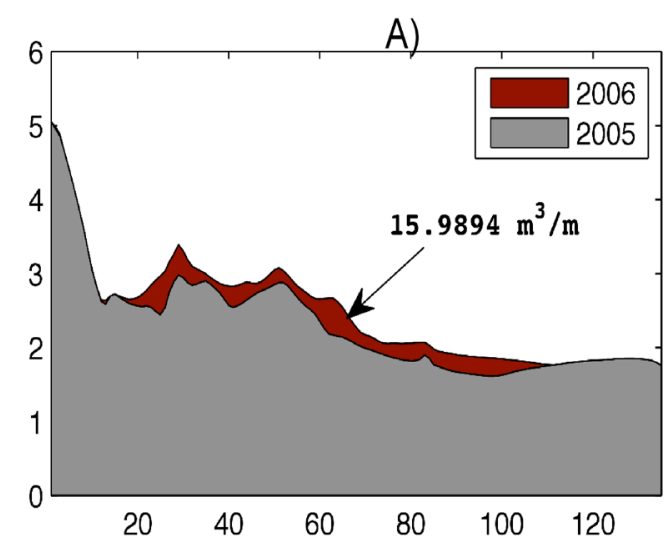

B)

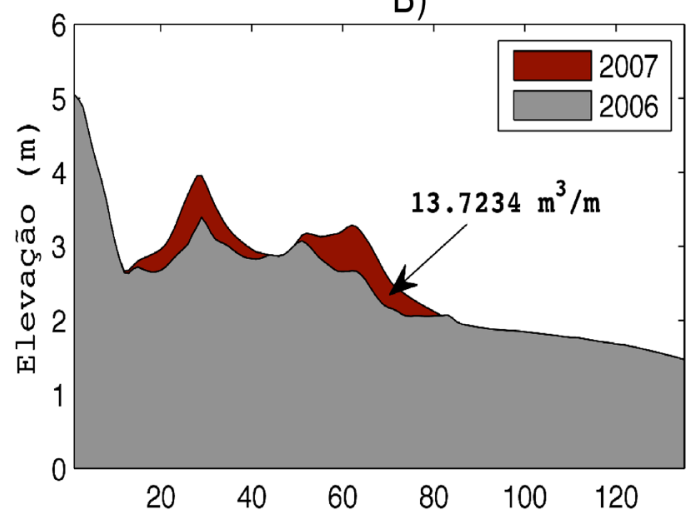

C)

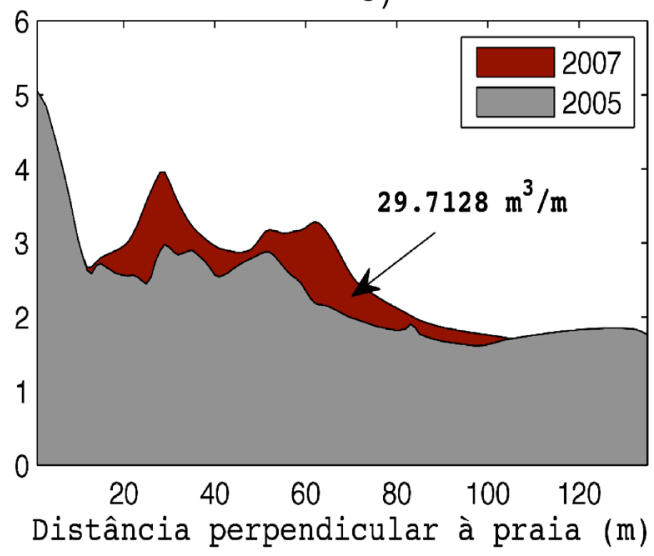

Figura 8. Evolução anual dos perfis topográficos na porção subaérea na praia do Cassino. A) Volume do pacote sedimentar depositado sobre a parte sub-aérea entre os anos de 2005 e 2006; B) Volume do pacote sedimentar depositado entre os anos de 2006 e 2007; C) Volume do pacote sedimentar depositado entre os anos de 2005 e 2007 , em $\mathrm{m}^{3} / \mathrm{m}$. 


\section{Discussões dos resultados}

Segundo Bagnold (1941), para que o processo de transporte de sedimento ocorra, a velocidade do vento deve superar a $5 \mathrm{~m} / \mathrm{s}$, a um metro de altura, considerando sedimentos esféricos, bem selecionados, com tamanho de grão areia. Nesse contexto, Calliari \& Klein (1993) identificam que o setor da Querência na praia do Cassino apresenta um percentual de $30,1 \%$ d e areia muito fina e $1,30 \%$ de areia média, com média em $\Phi$ de 2,5 (ou 0,18mm). Seguindo as teorias de transporte, propostas por Bagnold (1941), a composição de areias finas e muito finas facilitam o transporte e aumenta potencialmente à deriva eólica. Sherman \& Hotta (1990) identificam outros fatores que são determinantes para a formação das dunas como: o efeito do declive do terreno, da coesão sedimentar, da vegetação e características relativas ao grão.

A declividade do terreno pode causar distúrbios na velocidade de cisalhamento do vento. Variações na inclinação fazem com que ocorra uma aceleração ou desaceleração da velocidade do vento, podendo ocasionar turbulência, dificultando o início do transporte. Segundo Short \& Hesp (1982), praias dissipativas apresentaram menor distúrbio naestrutura do campo de vento superficial, dessa forma facilitando o transporte de sedimentos pelo vento. Figueiredo \& Calliari (2006) descrevem que o fato da praia do Cassino apresentar um alto percentual de areia muito fina $(>20 \%)$ indica uma baixa mobilidade do perfil praial, que auxilia a manter uma ampla largura com baixa mobilidade. Portanto, essas características do perfil da praia do Cassino permitem o desenvolvimento de uma ampla área de pós-praia, com declividade suave e pouco acidentada. Consequentemente, são criadas condições ideais para o desenvolvimento de uma larga pista de vento com baixos distúrbios no perfil de velocidade do vento, assim, facilitando o transporte eólico na região.

A partir de ensaios em laboratório, Hotta et al. (1984) quantificaram a influência da água contida no sedimento no transporte. A umidade e a água contida na superfície sedimentar, ou próxima a ela incrementa momento aos sedimentos, assim, dificultando que o vento os remobilize, necessitando de uma maior velocidadede cisalhamento do vento para iniciar o transporte. Os principais fenômenos responsáveis por controlar a quantidade de água no sedimento do pós-praia do Cassino são: a precipitação, o efeito das marés meteorológicas, spray salino (maresia) e a radiação solar. A precipitação tem por característica umidificar o sedimento sem modificar a estrutura morfológica formada por ele; o spray salino umidifica apenas as camadas mais superficiais da estrutura sedimentar, sendo rapidamente evaporado pela radiação solar; enquanto eventos de alta energia de ondas e elevação do nível do mar são responsáveis pela erosão do pós-praia, consequentemente alterando as estruturas morfológicas ali presentes e deixando a superfície inundada. Um gra- diente de umidade horizontal, perpendicular à linha de costa, pode ser definido durante a maior parte do tempo. A zona de estirâncio apresenta-se mais úmida devido ao frequente embate das ondas, enquanto o pós-praia apenas fica úmido durante eventos de maré meteorológica, chuvas e em menor intensidade devido à maresia. Entretanto, a maré meteorológica pode ser negativa, assim rebaixando o nível, durante a atuação de ventos fortes do quadrante nordeste, dessa forma aumentando a área exposta a essas condições de vento, assim potencializando o transporte.

A região das dunas frontais dificilmente fica exposta à ação da maré meteorológica, dessa forma as dunas frontais apresentariam menor força de coesão no sedimento durante a maior parte do tempo, isso diminuiria a velocidade críticade cisalhamento. Entretanto, a região das dunas frontais e embrionárias no setorda praia da Querência apresenta-se vegetada, fator que tem por característica dificultar o transporte do sedimento pelo vento. Portanto, essa análise indica que o sedimento menos coeso e mais fácil de ser transportado, na maior parte do tempo, é o encontrado na região do pós-praia. Sugerindo que o transportede sedimento é facilitado por ventos que consigam desenvolver uma maior pista de vento sobre o pós-praia, cujo componente principal apresenta-se no sentido paralelo à linha de costa.

Em uma análise mais detalhada, o vento pode ser identificado como o principal agente capaz de forçar o movimento do sedimento na porção subaérea da praia. Portanto, a compreensão de seus componentes, velocidade e direção, são fundamentais no desenvolvimento das dunas. A figura 9 traz o histograma percentual da direção e velocidade do vento ao longo dos anos de 2005, 2006 e 2007.

Nas regiões litorâneas, para um bom desenvolvimento das dunas é fundamental que o vento apresente velocidades suficientemente altas para colocar o sedimento em movimento e com um de seus componentes agindo perpendicular à linha de costa, no sentido oceano continente. Assim, a análise da figura 9 permite identificar que anualmente houve poucas mudanças no regime de vento. Tal fato justifica a pouca diferença entre as taxas de acresção médias dos sedimentos na porção subaérea (Fig.8). Entretanto, como identificado nas figuras, esse sedimento encontrava-se distribuído desigualmente sobre o pós-praia e dunas frontais, durante esses três anos. Portanto, uma análise mais detalhada do vento durante o período estudado permite identificar se existiram flutuações sazonais nos padrões dos regimes dos ventos (Fig.10) que justifica os diferentes padrões de deposição encontrados.

$\mathrm{Na}$ figura 10 as cores vermelhas indicam que o vento possui baixo potencial de transporte, enquanto os valores representados pelas cores laranja e amarelo apresentam ventos com velocidades acima de $5 \mathrm{~m} / \mathrm{s}$, que são os verdadeiros responsáveis por transportar o sedimento (Bagnold, 1941). Durante a maior parte 
do ano é possível identificar uma maior frequência dos ventos atuantes de forma positiva, ou seja, proporcionando que mais sedimento entre no sistema. Contudo, é durante a primavera e o verão que o vento apresenta o maior potencial de transporte de sedimentos para o continente.

Observando a figura 10 é perceptível que durante o período de primavera, em 2006, ocorreu uma predominância do vento nordeste, superior a $10 \%$ se comparado aos outros anos. 0 vento nordeste, por sua vez, apresenta componente predominantemente paralelo à orientação da linha de costa e tal fato justifica a deposição do sedimento principalmente sobre o pós-praia durante a primavera de 2006, conforme previamente mencionado e identificado nos perfis e nas imagens Argus (Guimarães, 2010).

Os ventos que apresentam principal caráter erosivo foram os de oeste, devido a sua orientação com a linha de costa. Segundo Krusche et al. (2002) os ventos de oeste estão associados ao término das frentes frias que permitem a inversão do anticiclone polar móvel. Segundo os mesmos, os ventos de sul e sudoeste, também muito frequentes, estão associados à passagem de frentes frias. 0 vento sudoeste possui uma inclinação paralela à linha de costa e alta intensidade, apresentando característica similar ao vento nordeste: de depositar sedimento no pós-praia. Todavia, o vento sudoeste encontra-se em um limite tênue, no qual a migração do anticiclone polar móvel próximo à costa pode alterar a direção do vento para oeste, vindo a ocasionar erosão nas dunas frontais. Como identificado por Guimarães (2010), o vento sudoeste também se apresentou responsável pela formação de dunas incipientes sobreo pós-praia, mas sua migração para oeste pode vir a ocasionar erosão no sistema.

Portanto, como pode ser observado nas figuras 5, 6 e 8, durante a primavera do ano de 2006 o sedimento tendeu a se depositar sobre o pós-praia em decorrência de uma maior incidência dos ventos de nordeste e sudoeste.
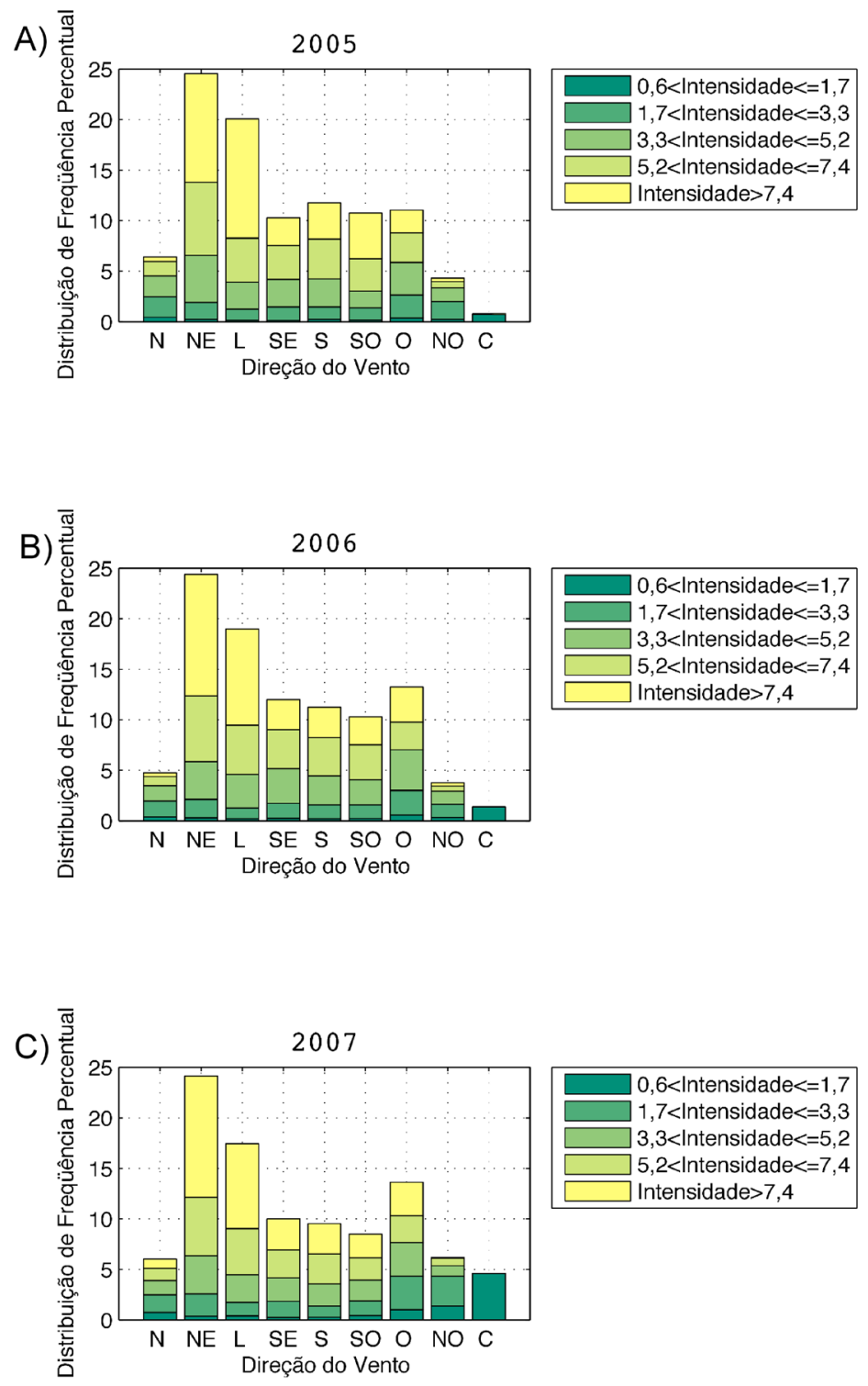

Figura 9. Histograma percentual de direção e velocidade anual do vento medido na estação da torre da praticagem da barra de Rio Grande para os anos de 2005 (A), 2006 (B) e 2007 (C). 

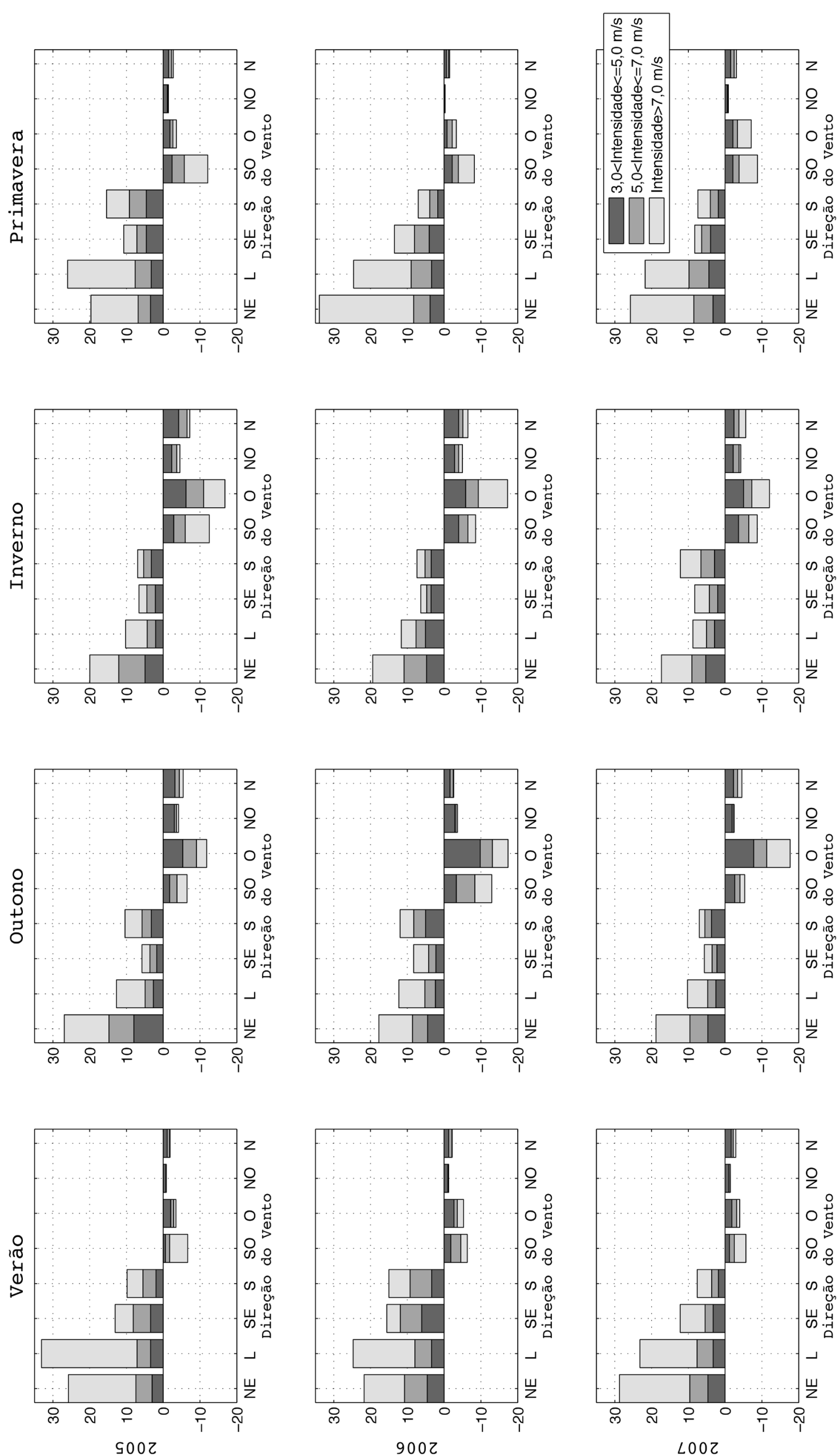

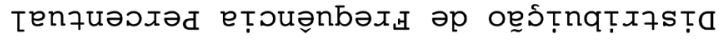

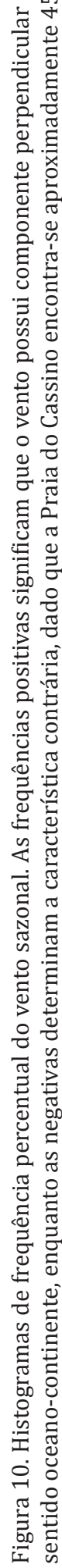


Os resultados das análises sinóticas mensais do Centro de Previsão do Tempo e Estudos Climáticos (CPTEC/INPE, 2006) permitem observar que nos meses de julho a novembro de 2006 houve uma forte presença do Jato Subtropical deslocado mais para o sul, o que impediu o avanço dos sistemas frontais e, assim, permitiu que o Anticiclone do Atlântico Sul dominasse sobre a região da praia do Cassino, com consequente predomínio do vento nordeste.

Durante o ano de 2006 também foi observada uma transição de um estado neutro para um El Niño fraco. Segundo Grimm (2003) durante a configuração de El Niño, o aquecimento superficial das águas do Pacífico equatorial diminuem a intensidade da subsidência da circulação da célula de Walker no leste do Pacífico, assim permitindo a formação de dois jatos que ultrapassam a barreira da Cordilheira dos Andes em alta atmosfera se propagando no sentido da América do Sul. Parte dessa massa desloca-se em direção à zona de convergência subtropical, assim juntando-se ao jato subtropical e o intensificando. Essa intensificação do jato subtropical foi identificada como a causa de um bloqueio atmosférico no deslocamento dos sistemas frontais observado nos meses de julho, agosto, setembro, outubro e novembro de 2006.

A alteração do regime dos ventos locais refletiu seu comportamento na costa. Embora as influências do El Niño sobre o vento local na praia do Cassino não sejam facilmente relacionadas, os dados de ION, juntamente com a análise das sínteses sinóticas do CPTEC sugerem que essa anomalia positiva de temperatura no Pacífico Sul gerou a intensificação do Jato Subtropical e consequentemente, modificou os ventos da costa riograndense.

Embora as dunas incipientes desempenhem importante papel na captação inicial de sedimento, parte da areia continua sendo levada pelo vento em direção ao continente. Assim, a interceptação desse fluxo e sua deposição é realizada pela vegetação. Quando o sedimento encontra as dunas frontais ele tende a se estabilizar em decorrência de um incremento na tensão superficial devido ao aumento no coeficiente de rugosidade do solo. Segundo Hesp (1981), esse incremento no coeficiente de rugosidade do solo diminui o potencial de transporte pelo vento.

A análise das imagens daytimex da câmera um (Fig. 11.a) permitem identificar uma intensificação da ocupação pela vegetação na superfície das dunas devido ao aumento de valores de pixels de cor verde na imagem, sugerindo assim, um crescimento da vegetação sobre as dunas frontais. A figura 11B nos auxilia a identificar como ocorreu essa variação ao longo do tempo. A última imagem do quadro identifica que houve um aumento da densidade vegetal ao longo de dois anos, sobre a região das dunas frontais. Dessa forma, baseado nas imagens é possível perceber que entre 2005, 2006 e 2007 houve uma evolução na densidade vegetal sobre as dunas frontais e um avanço da linha da vegetação em direção ao mar.
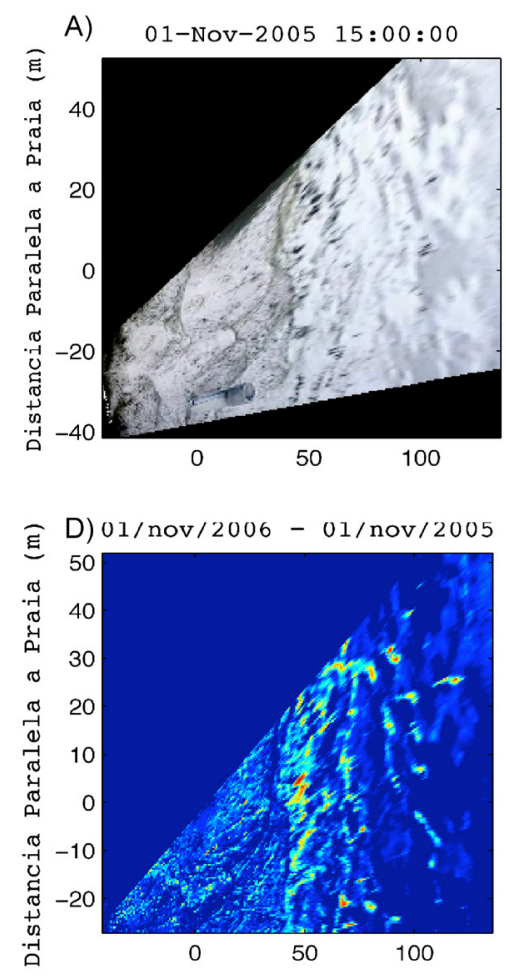
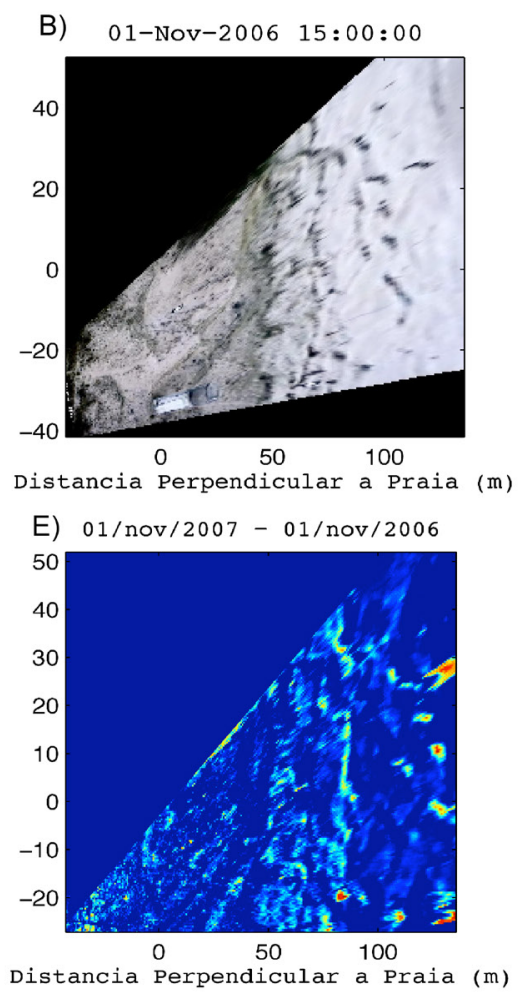
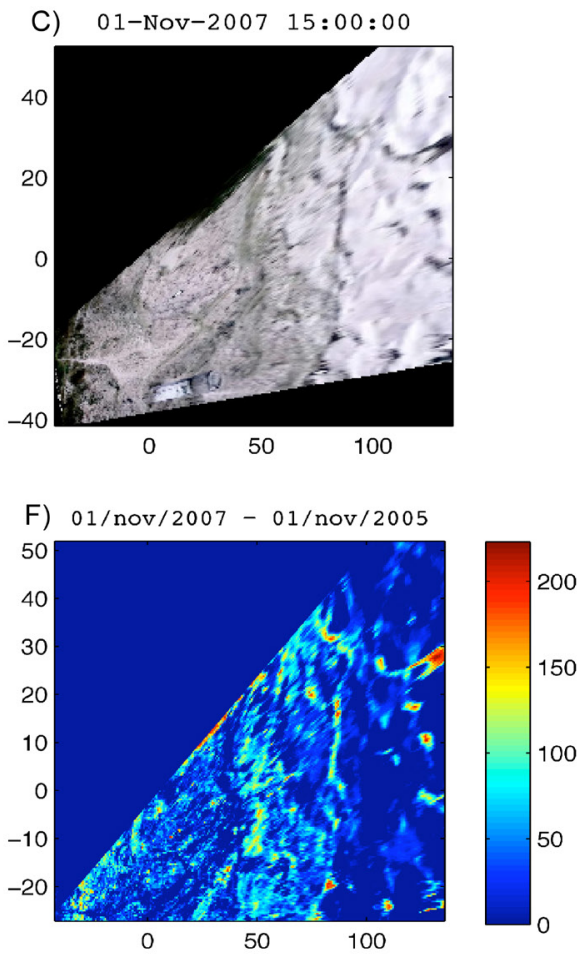

Figura 11. Evolução temporal da densidade vegetal sobre as dunas frontais. A, B e C) representam as imagens daytimex da câmera um para os dias de primeiro de novembro para os anos de 2005, 2006 e 2007 respectivamente; D, E e F) representam a diferença temporal de um recorte das daytimex (Fig. 11ABC). 
A partir de dados medidos em campo e observados nas imagens, foi identificado que nas regiões que apresentaram maior crescimento das dunas houve um predomínio da vegetação de Panicumracemosum (setor I, fig.12), enquanto as áreas mais afastadas da praia apresentaram maior diversidade vegetal, com a vegetação de Pracemosum sendo substituída por outras espécies vegetais (setor II, fig. 12). As principais espécies identificadas nestes setores estão referidas na figura 13 e sua ocupação é identificada na figura 12 .

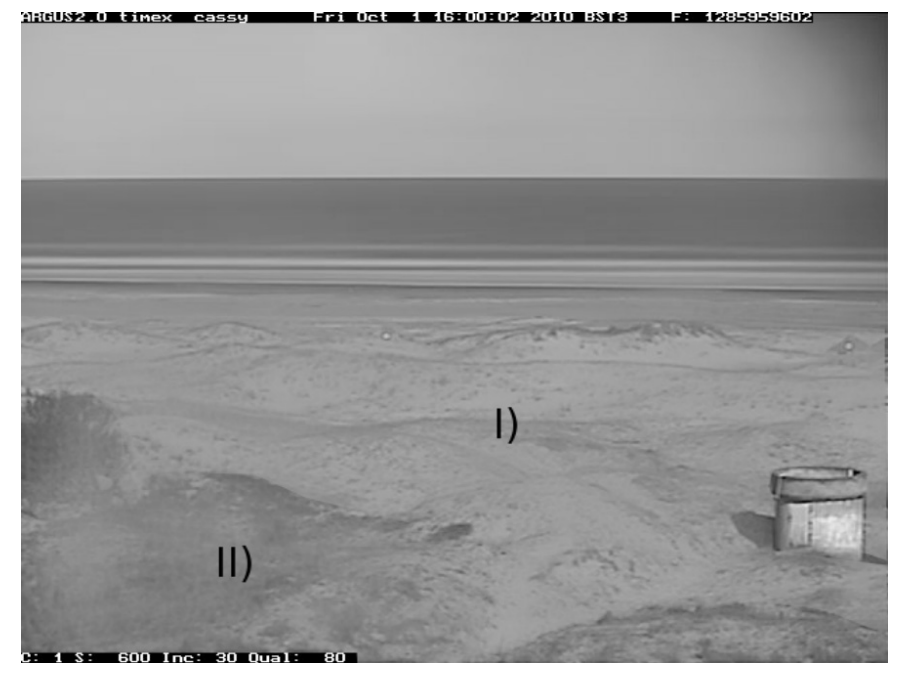

Figura 12. Zonação da vegetação encontrada em frente à câmera 1 do sistema Argus. As espécies vegetais estão identificadas segundo os setores na figura 13 .

Segundo Seeligeret al. (2004) a espécie Panicumracemosum, também conhecida como capim das dunas, é bem adaptada ao ambiente de dunas costeiras. 0 capim das dunas responde ao fluxo de areias da praia com um vigoroso crescimento de sua haste e folhas, proporcionando ao seu redor a captura de novos sedimentos que estimulam novo crescimento. Assim, a contínua deposição de sedimento é fixada pela densa rede de rizomas e raízes que vão lentamente construindo as dunas frontais. Segundo os mesmos autores,essa gramínea possui hastes flexíveis, com folhas estreitas e finas que emergem dos nós dos rizomas assim favorecendo a captação de areia transportada pelo vento. Portanto, o aumento do suprimento de areia rica em nutrientes proporciona um contínuo crescimento do sistema subterrâneo e da parte aérea das estruturas dessa espécie vegetal, assim a caracterizando como "areia dependente".

0 alto suprimento de areia encontrado no sistema de dunas frontais da praia do Cassino, corrobora com o crescimento de Panicumracemosum sobre as dunas frontais, explicando a deposição de sedimento nas mesmas. Dessa forma, o sistema criado entre vegetação, transporte e deposição é amplificado nesse setor da praia do Cassino, resultando em uma deposição anual de um grande volume sedimentar.
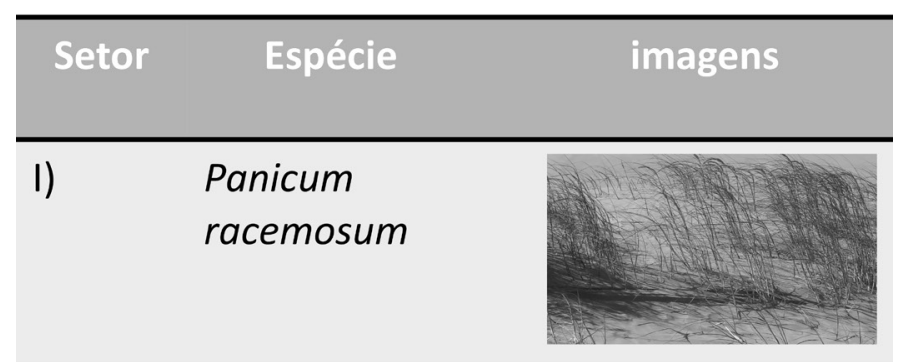

II)
Senecio crassiflorus

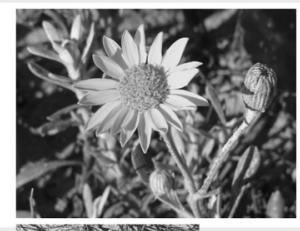

\section{II) Androtrichum triynum}

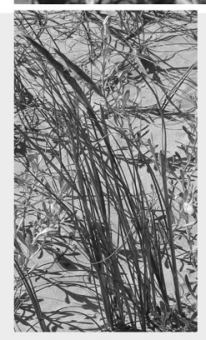

II)

\section{Andropogon arenarius}

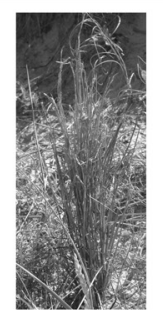

\section{II) Hydrocotyle bonariensis}

Figura 13. Principais espécies vegetais identificadas sobre as dunas frontais no campo de visada da câmera 1 do sistema Argus (Fig. 12).

\section{Conclusões}

O sistema de videomonitoramento Argus, juntamente com dados de perfis topográficos e meteorológicos permitiu quantificar importantes processos sedimentares subaéreos e damorfodinâmica das dunas, nesse setor da praia do Cassino. A base de dados utilizada nesse trabalho identificou uma evolução espaço-temporal do perfil de dunas predominantemente progradante, apresentando um aumento da densidade vegetacional e do volume sedimentar, tanto no sentido vertical quanto horizontal. Portanto, a partir dessa base de dados, foi possível estimar uma taxa de acresção média anual de $14 \mathrm{~m}^{3} / \mathrm{m}$ para um mesmo alinhamento das dunas frontais até a zona de estirâncio.

A análise conjunta das imagens Argus e dos dados de vento permitiram identificar que o principal agente modelador do sedimento na porção subaérea foi à alta frequência de ventos com velocidades superiores a $5 \mathrm{~m} / \mathrm{s}$ provenientes dos quadrantes de NE a SW. Essa alta frequência de ventos fortes determina um grande potencial de transporte eólico, enquanto a ocorrência 
desse vento predominando no sentido praia dunas é fundamental para a formação das dunas frontais. Portanto, opadrão de ventos de Rio Grande juntamente com as condições naturais da praia do Cassino favoreceu o transporte de sedimento, paralelo à praia e em direção ao continente. Todavia, uma maior taxa de deposição do sedimento sobre o pós-praia foi encontrada durante o evento de El Niño de 2006, devido a uma maior frequência do vento NE.

Interagindo diretamente nos processos físicos de transporte e deposição do sedimento a vegetação representada por Panicumracemosum reagiu de forma positiva à deposição sedimentar favorecendo o seu crescimento que, por sua vez, potencializou a entrada de mais sedimentos nas dunas frontais. Para observar esse processo, a ferramenta Argus mostrou-se essencial, pois permitiu avaliar dados pretéritos da cobertura vegetal, os quais seriam inviáveis sem o uso dessa ferramenta.

Agradecimentos -Estetrabalho constitui parte do trabalho de conclusão de curso do primeiro autor, desenvolvido junto ao Curso de Oceanologia da Universidade Federal do Rio Grande. Os autores agradecem à FAPERGS pelos subsídios financeiros recebidos. Os mesmos também agradecem a César Cordazzo do Laboratório de Ecologia Vegetal do Instituto de Oceanografia da Universidade Federal do Rio Grande por auxiliar na identificação das espécies vegetais presentes no local de estudo.

\section{Referências}

Bagnold, R.A. 1941. The Physics of Blown Sand and Desert Dunes. London, John Wiley \& Sons, 320p.

Calliari, L., Pereira, P.S., Oliveira, A.O. \& Figueiredo, S.A. 2005. Variabilidade das Dunas Frontais no Litoral Norte e Médio do Rio Grande do Sul, Brasil. Gravel, 3:15-30.

Calliari, L.J. \& Klein, A.H. 1993.Características Morfodinâmicas e Sedimentológicas das Praias Oceânicas Entre Rio Grande e Chuí, RS. Pesquisas em Geociências, 20(1):48-56.

Carter, R.W.G. 1988. Coastal environments: An introduction to the physical, ecological and cultural systems of coastlines. London,Academic Press, 499p.

Carvalho, R., Silva, K.,\& Crivellaro, C. 2008. Gestão Ambiental das Dunas Costeiras manejo e conservação. Rio Grande, Núcleo de Educação e Monitoramento Ambiental NEMA, 32p.

CPTEC/INPE. Centro de Previsão do Tempo e Estudos Climáticos/Instituto Nacional de Pesquisas Espaciais. 2006. Boletim Técnico de Análise Sinótica, São Paulo, CPTEC, 15p. Disponível em: <http://www.cptec.inpe.br/>. Acessado em 01 nov. 2010.

Figueiredo, S.A \& Calliari, L.J. 2006. Sedimentologia e suas implicações na morfodinâmica das praias adjacentes às desembocaduras da linha de costa do Rio Grande do Sul. Gravel, 4: 47-87

Guedes, R.M., Calliari, L.J.\& Pereira, P.S. 2009. Morfodinâmica da praia e zona de arrebentação do Cassino, RS, através de técnicas de vídeo imageamento e perfis de praia. Pesquisas em Geociências, 36: 165-180.

Manuscrito 535.

Editores: Iran C. S. Corrêa \& Maria do Carmo Lima e Cunha.
Guimarães, P.V. 2010. Morfodinâmica do pós-praia e duna frontal com auxílio de vídeo-monitoramento: Cassino, $R S$. Rio Grande,75p. Trabalho de Conclusão de Curso, Curso de Oceanologia, Instituto de Oceanografia, Universidade Federal do Rio Grande.

Grimm, A.M. 2003. The El Niño Impact on the Summer Monsoon in Brazil: Regional Processes versus Remote Influences. Society, 16:263-280.

Hesp, P.A. 1981. The Formation of Shadow Dunes. Journal of Sedimentary Research, 51:101-112.

Holland, K., Holman, R., Lippmann, T., Stanley, J. \& Plant, N. 1997. Practical use of video imagery in near shore oceanographic field studies. Journal of Oceanic Engineering, 22(1):81-92.

Holman, R. \& Stanley, J. 2007.The history and technical capabilities of Argus. Coastal Engineering, 54:477-491.

Hotta,S., Kubuta, S., Katori,S. \& Horikawa, K. 1984. Sand transport by wind on wet surface. In: PROCEEDINGS OF THE $19^{\mathrm{TH}}$ COASTAL ENGINEERING CONFERENCE, New York, ASCE, p. 1265-1281.

Krusche, N., Saraiva, J.M.B. \& Reboita, M. 2002. Normais Climatológicas Provisórias de 1991 a 2000 para Rio Grande, $R S$. Santa Maria, Universidade Federal de Santa Maria, Editora Universitária, 84p.

Lélis, R.J.F. 2003. Variabilidade da Linha de Costa Oceânica Adjacente às Principais Desembocaduras do Rio Grande do Sul. Rio Grande, 79p. Monografia de Conclusão de Curso, Curso de Oceanologia, Departamento e Geociências, Universidade Federal do Rio Grande.

Nimer, E. 1989. Climatologia do Brasil. Rio de Janeiro, IBGE-DERNA, 421p.

NOAA.National Oceanic and Atmospheric Administration.2010. ENSO Cycle: Recent Evolution, Current Status andPredictions, Estados Unidos da América, NOAA, 37p. Disponível em <http://www.cpc.noaa.gov/>, Acessado em 09 nov. 2010.

Pereira, P.S., Calliari, L.J., Guedes, R.M.C. \& Schettini, C.A.F. 2012. Variabilidade temporal da posição dos bancos arenosos da praia do Cassino (RS): uma análise através de imagens de vídeo. Pesquisas em Geociências, 39: 195-211.

Psuty, N. 1988.Sediment Budget and Dune/Beach Interaction. Journal of Coastal Research, 3:1-4.

Seeliger, U., Cordazzo, C. \& BarcelosL. 2004. Areias do Albardão: um guia ilustrado do litoral no extremo sul do Brasil. Rio Grande, Ecoscientisa, 95p.

Sherman, D.J. \& Hotta, S. 1990. Aeolian sediment transport: the theory and measurements. In: Nordstrom, K.F., Psuty, N. \& Carter, B. (Ed.). Coastal Dunes: Form and Process. Chichester, John Wiley \& Sons, p. 17-37.

Short, A.D. \& Hesp, P.A. 1982, Waves beach and dune interactions in southeastern Australia. Marine Geology, 48(1): 259-284

Tomazelli, L.J. 1993. 0 regime de ventos e taxa de migração das dunas eólicas costeiras do Rio Grande do Sul, Brasil. Pesquisas em Geociências, 20(1): 18-26.

Wright, L.D. \& Short, A.D. 1984. Morphodynamic variability of surf zones and beaches: A synthesis. Marine Geology, 56:93-118.

Zhou, J. \& Lau, K. 1998. Does a Monsoon Climate Exist over South America? Jornal of Climate, 11:1020-1040. 
